\title{
Photoluminescence and Raman Spectroscopy Studies of Carbon Nitride Films
}

\author{
J. Hernández-Torres, ${ }^{1}$ A. Gutierrez-Franco, ${ }^{1}$ P. G. González, ${ }^{2}$ \\ L. García-González, ${ }^{1}$ T. Hernandez-Quiroz, ${ }^{1}$ L. Zamora-Peredo, ${ }^{1}$ \\ V. H. Méndez-García, ${ }^{3}$ and A. Cisneros-de la Rosa ${ }^{3}$ \\ ${ }^{1}$ Centro de Investigación en Micro y Nanotecnología, Universidad Veracruzana, 94292 Boca del Río, VER, Mexico \\ ${ }^{2}$ CONACYT Research Fellow-Centro de Ingeniería y Desarrollo Industrial, 76125 Querétaro, QRO, Mexico \\ ${ }^{3}$ Coordinación para la Innovación y Aplicación de la Ciencia y Tecnología, Universidad Autónoma de San Luis Potosí, \\ 78210 San Luis Potosí, SLP, Mexico
}

Correspondence should be addressed to J. Hernández-Torres; julihernandez@uv.mx and P. G. González; pedro.gonzalez@cidesi.edu.mx

Received 9 November 2015; Accepted 27 January 2016

Academic Editor: Jau-Wern Chiou

Copyright (C) 2016 J. Hernández-Torres et al. This is an open access article distributed under the Creative Commons Attribution License, which permits unrestricted use, distribution, and reproduction in any medium, provided the original work is properly cited.

\begin{abstract}
Amorphous carbon nitride films with N/C ratios ranging from 2.24 to 3.26 were deposited by reactive sputtering at room temperature on corning glass, silicon, and quartz as substrates. The average chemical composition of the films was obtained from the semiquantitative energy dispersive spectroscopy analysis. Photoluminescence measurements were performed to determine the optical band gap of the films. The photoluminescence spectra displayed two peaks: one associated with the substrate and the other associated with $\mathrm{CN}_{x}$ films located at $\approx 2.13 \pm 0.02 \mathrm{eV}$. Results show an increase in the optical band gap from 2.11 to $2.15 \mathrm{eV}$ associated with the increase in the $\mathrm{N} / \mathrm{C}$ ratio. Raman spectroscopy measurements showed a dominant $D$ band. $I_{D} / I_{G}$ ratio reaches a maximum value for $\mathrm{N} / \mathrm{C} \approx 3.03$ when the optical band gap is $2.12 \mathrm{eV}$. Features observed by the photoluminescence and Raman studies have been associated with the increase in the carbon $\mathrm{sp}^{2} / \mathrm{sp}^{3}$ ratio due to presence of high nitrogen content.
\end{abstract}

\section{Introduction}

Light elements based materials which associate $2 p$ and $3 p$ elements, mainly from columns III to $\mathrm{V}$ of the periodic system, are of great interest due to their physicochemical properties. In this sense, the elevate hardness, chemical inertia, good thermal conductivity, optical transparency (on a wide wave number range), highly refractory character, electric insulator behavior, and high band gap values are the most representative [1].

Concerning their production, two main routes of synthesis have been developed to obtain carbon nitrides as thin films or as bulk materials. Many publications devoted to the synthesis of $\mathrm{CN}_{x}$ thin films have jointly concluded that the existence of the crystalline stoichiometric $\mathrm{C}_{3} \mathrm{~N}_{4}$ phase has not been clearly evidenced yet. To date, the so-obtained deposits are generally amorphous and can eventually contain some nanometric $\mathrm{CN}_{x}$ crystallites [2]. However, these amorphous thin films seem to present interesting electrical, mechanical, tribological, and optical properties [3-6].

In recent years, study of the optical properties of amorphous carbon nitrides $\left(\alpha-\mathrm{CN}_{x}\right)$ films became an interesting field. The reported characteristics have provided evidence for a possible utilization in optoelectronic devices, such as electroluminescence devices [7] or photovoltaic solar cells. In this sense, the optical properties of $\alpha-\mathrm{CN}_{x}$ have been extensively studied via diverse techniques such as Raman, photoluminescence (PL), or absorption spectroscopy. Typically, the Raman spectra of carbon nitrides, measured at any excitation energy, have a similar form to those of $\mathrm{N}$-free amorphous carbons, that is, showing the $D$ and $G$ bands. The existence of a $D$ band indicates the presence of aromatic rings. The $G$ band for carbon materials arises from vibration of all $\mathrm{sp}^{2}$ sites and in both chain and ring configurations. 
The intensity of a $D$ peak, however, arises only from clusters of $\mathrm{sp}^{2}$ sites in six fold aromatic rings [8]. Most of the time, the available literature about carbon nitrides describes films with nitrogen content below 50\%; in there, the observed intensity of the $G$ band is usually higher than that of the $D$ band.

On the other hand, PL is an alternative method to explore the optical gap in thin films prepared from different approaches. This technique has been used, for instance, in amorphous nitrogen-rich carbon nitride $\left(\mathrm{CN}_{x}\right)$, films prepared by inductively coupled plasma chemical vapour deposition [9], amorphous carbon nitride thin films grown by plasma decomposition of a feedstock of $\mathrm{CH}_{4}$ and $\mathrm{N}_{2}$ [10], amorphous carbon oxynitrides $\alpha-\mathrm{CN}_{x} \mathrm{O}_{y}$ films made by a nitrogen radical sputter method and by the layer-by-layer method [11], carbon nitride films grown by vapor transport of carbon nitride powders [12], boron-doped amorphous carbon nitride thin films synthesized by microwave electron cyclotron resonance-plasma chemical vapor deposition [13], amorphous carbon nitride (a-CN) films deposited by reactive R.F. sputtering source with a graphite target [14], and hydrogen amorphous carbon nitrile particles grown by $\mathrm{CH}_{4} / \mathrm{N}_{2}$ radio-frequency plasma [15]. The use of PL on carbon nitride films has shown a wide peak near to $2 \mathrm{eV}$, where the signals are associated mainly with $\pi$ and $\pi^{*}$ states or lone-pair electrons $[7,9,14]$.

In addition, absorption spectroscopy is used to determine the Tauc gap and the $E_{04}$ band gap [9]. In $\alpha$-CN films, the hydrogen content is an essential parameter to explain the behavior of the optical gap, but this relationship is still unclear. Some reports mention that the optical energy gap decreases as the nitrogen content increases $[9,10]$. However, various manuscripts describe the opposite behavior [16]. In this contribution we analyze, by using spectroscopy techniques, a series of carbon nitride films with high N/C ratio, which were deposited on three types of substrates, glass, silicon, and quartz, via reactive sputtering system. The nitrogen content was determined by semiquantitative X-ray energy dispersive spectroscopy (EDS) analysis; the optical gap was obtained at room temperature from the PL measurements. In addition, Raman spectroscopy was used to explore $\mathrm{sp}^{2}$ hybridization state and the average microstructure of the deposited $\alpha-\mathrm{CN}_{x}$ films and substrates.

\section{Experimental Details}

Carbon nitride films (labeled as S1-S6) were deposited on glass by a reactive sputtering system, in an argon-nitrogen atmosphere, using graphite (purity of $99.99 \%$, diameter $\approx$ $5.08 \mathrm{~cm}$, and thickness $\approx 0.32 \mathrm{~cm}$ ) as target. The $A r / \mathrm{N}_{2}$ ratio was selected between 2.08 and 3.47 (see Table 1). The temperature of the substrates was set at $25^{\circ} \mathrm{C}$. We proceeded to initiate the vacuum in the growth chamber, reaching a value of $2.5 \times 10^{-6}$ Torr. However, in the argon/nitrogen atmosphere, the working pressure varied between $5.4 \times 10^{-2}$ and $6.2 \times 10^{-2}$ Torr. In addition, two more samples were deposited on $\mathrm{Si}$ and quartz substrates, respectively, in order to compare the PL spectra and identify the substrate contribution. The sputtering system was provided with flowmeters to accurately
TABLE 1: Nomenclature, synthesis parameters, and PL results for the $\mathrm{CN}_{x}$ films.

\begin{tabular}{lcccc}
\hline Sample & Substrate & $\mathrm{Ar} / \mathrm{N}_{2}$ & $\mathrm{~N} / \mathrm{C}$ & PL peak $(\mathrm{eV})$ \\
\hline S1 & Glass & 2.08 & $2.24 \pm 0.03$ & 2.11 \\
S2 & Glass & 2.20 & $2.63 \pm 0.01$ & 2.12 \\
S3 & Glass & 2.39 & $3.03 \pm 0.02$ & 2.12 \\
S4 & Glass & 2.83 & $3.10 \pm 0.10$ & 2.13 \\
S5 & Glass & 3.00 & $3.16 \pm 0.09$ & 2.13 \\
S6 & Glass & 3.47 & $3.26 \pm 0.02$ & 2.15 \\
S7 & Silicon & 3.47 & 2.78 & 2.13 \\
S8 & Quartz & 3.47 & 3.28 & 2.13 \\
\hline
\end{tabular}

control the $\mathrm{Ar}$ and $\mathrm{N}_{2}$ flows into the deposition chamber. The samples were deposited by maintaining the electrode spacing at $25 \mathrm{~mm}$ and setting a power of $250 \mathrm{~W}$. The deposition time was chosen in order to achieve the same thickness in all the samples. The semiquantitative nitrogen content of the films was estimated by EDS using an XFlash-4010-Bruker microanalyzer system; the N/C ratios are shown in Table 1. PL measurements were performed using a $325 \mathrm{~nm} \mathrm{HeCd}$ Melles Griot laser as excitation source at $15 \mathrm{~mW}$, a $500 \mathrm{~mm}$ Acton monochromator, and a Spec-10 CCD camera system (Princeton Instruments). For Raman measurements, a microRaman spectrometer was used with a HeNe laser at $20 \mathrm{~mW}$ as excitation source, on a Dilor micro-Raman spectrometer with a $632.8 \mathrm{~nm}$ HeNe laser.

\section{Results and Discussion}

3.1. $\mathrm{CN}_{x}$ Films Deposited on Glass as Substrate. The approximate chemical composition of the prepared $\mathrm{CN}_{x}$ films was estimated by using semiquantitative EDS analysis. Results collected in Table 1 show that N/C ratio of the films deposited on glass ranges between 2.24 and 3.26, as a result of increasing the $\mathrm{Ar} / \mathrm{N}_{2}$ flow ratio from 2.08 to $3.47 \mathrm{~mL}$.

From Table 1, it is possible to detect that variations in the N/C ratio are reflected in a slight increase in the optical gap values from 2.11 to $2.15 \mathrm{eV}$. This behavior is in agreement with the reported data for amorphous $\mathrm{CN}_{x}$ films $[9,10,16]$, although there are few works with N/C ratio higher than 2.

Figure 1 shows the room temperature PL spectra of the samples deposited on glass as substrate. Here, all the films display a broad maximum located at $\approx 2.13 \pm 0.02 \mathrm{eV}$. However, S4 and S6 present another more intense maximum, located at $\approx 1.7 \mathrm{eV}$. The behavior of the intensity of these peaks does not show a relation ascribed to the N/C ratio. However, Plass et al. reported two wide maxima positioned close to the optical Tauc gap and $E_{04}$ gap (close to $2.1 \mathrm{eV}$ and $2.4 \mathrm{eV}$ ) whose origin cannot be definitely clarified [9].

In order to identify a possible contribution derived from the substrate (glass) on the PL spectra of the films, we have made PL measurements in S4 (taken as reference) in the raw substrate and after the growth of the $\mathrm{CN}_{x}$ film. Figure 2 shows the resulting spectra. The PL spectrum of the substrate shows a maximum located at $\approx 1.7 \mathrm{eV}$, as displayed by $\mathrm{S} 4$. This feature indicates that this contribution is originated 
TABLE 2: Collected data obtained from the $D$ and $G$ bands of the Raman spectroscopy analyses.

\begin{tabular}{|c|c|c|c|c|c|c|c|c|c|c|c|}
\hline \multirow{2}{*}{ Sample } & \multicolumn{2}{|c|}{ Band position $\left(\mathrm{cm}^{-1}\right)$} & \multicolumn{2}{|c|}{ Band intensity } & \multirow{2}{*}{$I_{D} / I_{G}$} & \multicolumn{2}{|c|}{ FWHM } & \multicolumn{2}{|c|}{$L_{a}(\mathrm{~nm})$} & \multirow{2}{*}{$G_{\text {disp }}\left(\mathrm{cm}^{-1}\right)$} & \multirow{2}{*}{$\rho\left(\mathrm{g} / \mathrm{cm}^{3}\right)$} \\
\hline & $D$ & $G$ & $D$ & $G$ & & $D$ & $G$ & TK & FR & & \\
\hline S1 & 1349 & 1565 & 0.67 & 0.34 & 1.97 & 275 & 100 & 1.98 & 2.52 & 0.22 & 2.76 \\
\hline S2 & 1336 & 1558 & 0.64 & 0.25 & 2.54 & 328 & 101 & 2.26 & 1.95 & 0.24 & 2.85 \\
\hline S3 & 1335 & 1564 & 0.69 & 0.25 & 2.77 & 332 & 99 & 2.35 & 1.79 & 0.22 & 2.76 \\
\hline S4 & 1349 & 1565 & 0.52 & 0.26 & 1.96 & 272 & 93 & 1.98 & 2.77 & 0.22 & 2.76 \\
\hline S5 & 1350 & 1568 & 0.75 & 0.42 & 1.79 & 272 & 109 & 1.89 & 2.52 & 0.21 & 2.68 \\
\hline S6 & 1355 & 1566 & 0.59 & 0.37 & 1.61 & 247 & 102 & 1.80 & 3.07 & 0.22 & 2.76 \\
\hline S7 & 1349 & 1565 & 0.67 & 0.34 & 1.97 & 275 & 100 & 1.98 & 2.52 & 0.22 & 2.76 \\
\hline S8 & 1336 & 1559 & 0.64 & 0.25 & 2.54 & 328 & 101 & 2.25 & 1.95 & 0.24 & 2.85 \\
\hline
\end{tabular}

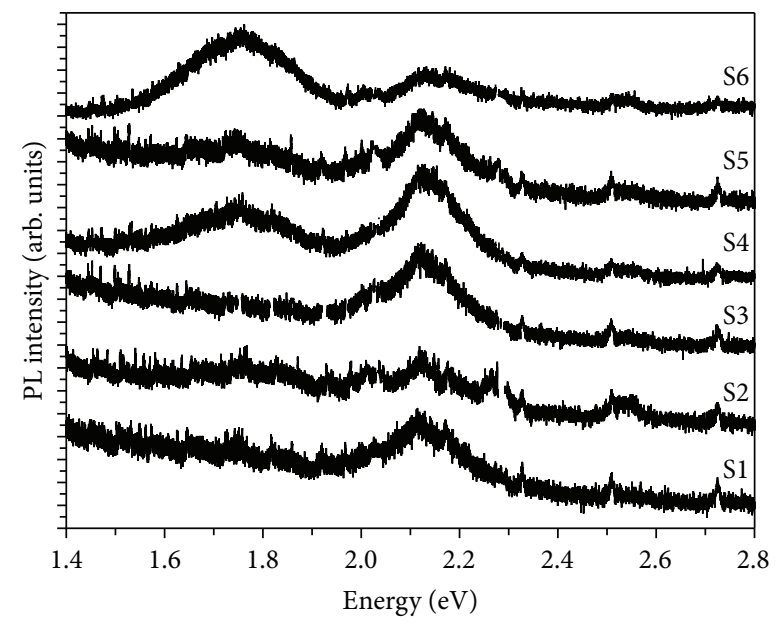

FIGURE 1: Room temperature PL spectra of $\alpha-\mathrm{CN}_{x}$ films deposited on glass as substrate.

by the glass, while the maximum observed at $\approx 2.11 \mathrm{eV}$ is associated with the carbon nitride films. On the other side, considering the energy of this last maximum and the model of density of states about $\alpha-\mathrm{CN}_{x}$ films reported elsewhere $[9,11]$, it is possible to establish that the peak at $\approx 2.11 \mathrm{eV}$ is associated with the optical gap of carbon nitride film. The high nitrogen content is responsible for the narrow peak, which is originated by the lon pair- $\pi^{*}$ state transitions. Other authors have reported much wider PL maximum due to low nitrogen content [9-15].

Figure 3 shows the first-order Raman spectra for the S1S6 films. Here it is possible to observe two characteristic bands frequently detected in carbon nitride films [7, 14, 17] which are also typical bands for disordered carbon materials: the so-called graphite $(G)$ band at $\approx 1580-1600 \mathrm{~cm}^{-1}$ and the disorder-induced $(D)$ band at $\approx 1300-1350 \mathrm{~cm}^{-1}[18,19]$. The $G$ band corresponds to the in-plane bond-stretching motion of carbon atoms in $\mathrm{sp}^{2}$ configuration with $E_{2 \mathrm{~g}}$ symmetry. The $D$ band is a breathing mode with $A_{1 \mathrm{~g}}$ symmetry which is forbidden in pristine graphite and becomes active in disordered graphite-like structures. The absence of the characteristic second-order $2 D\left(\approx 2700 \mathrm{~cm}^{-1}\right)$ and $2 G\left(\approx 3250 \mathrm{~cm}^{-1}\right)$ bands related to the tridimensional $\mathrm{ABAB}$ stacking of the graphene

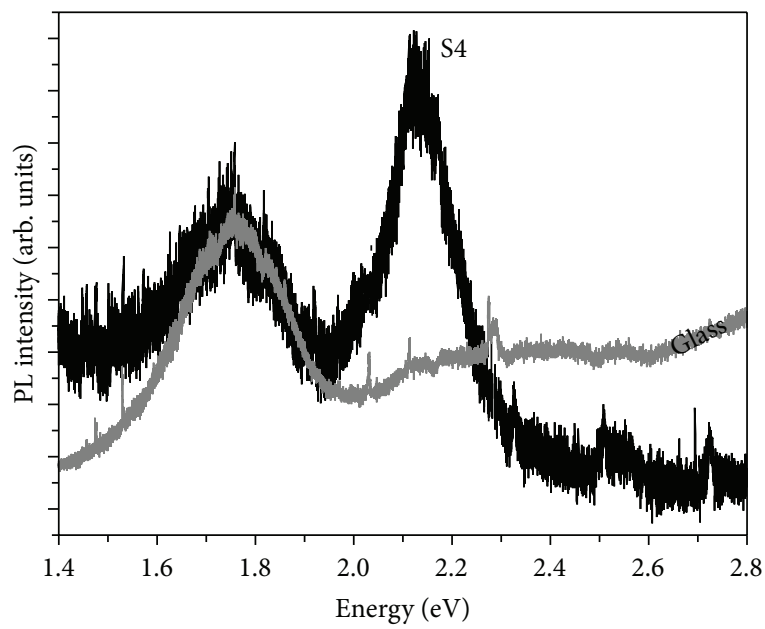

FIgURE 2: Comparative PL spectra of the substrate (glass) as received and after deposition of the $\mathrm{CN}_{x}$ film (S4).

layers in prefect graphite materials [20] and the graphite crystallite size [21] also confirms the highly disordered nature of these films.

Figure 3 also includes the Lorentz fitting of the Raman spectra for the S1-S6 series. The fitting curves are placed in down of the original bands and the numerical results are collected in Table 2. The Raman shift of the $G$ and $D$ bands is difficult to observe visually on the spectra. However, in Figure 3 , the differences in the intensity, emerging from the Lorentz fitting, clearly show that the intensity of $D$ is higher compared to the $G$ band intensity. In the collected results derived from the fitting of the Raman spectra (Table 2), the $G$ band is slightly shifted about $1563 \pm 5 \mathrm{~cm}^{-1}$ as a result of the saturation in the $G$ peak dispersion. This effect is derived from the high excitation energy produced by the HeNe laser operating at $632.8 \mathrm{~nm}$ [22].

In Table 2, it is possible to detect the shifting of the $G$ band to lower values (up to $1558 \mathrm{~cm}^{-1}$ ) for those samples with N/C ratio $\leq 3.03$ suggesting an increase in the bonding disorder and decrease of the $\mathrm{sp}^{3}$ content. However, for those samples with N/C ratio $\geq 3.16$, the $G$ band is shifted to higher values (up to $1568 \mathrm{~cm}^{-1}$ ), indicating that the bonding presents the 

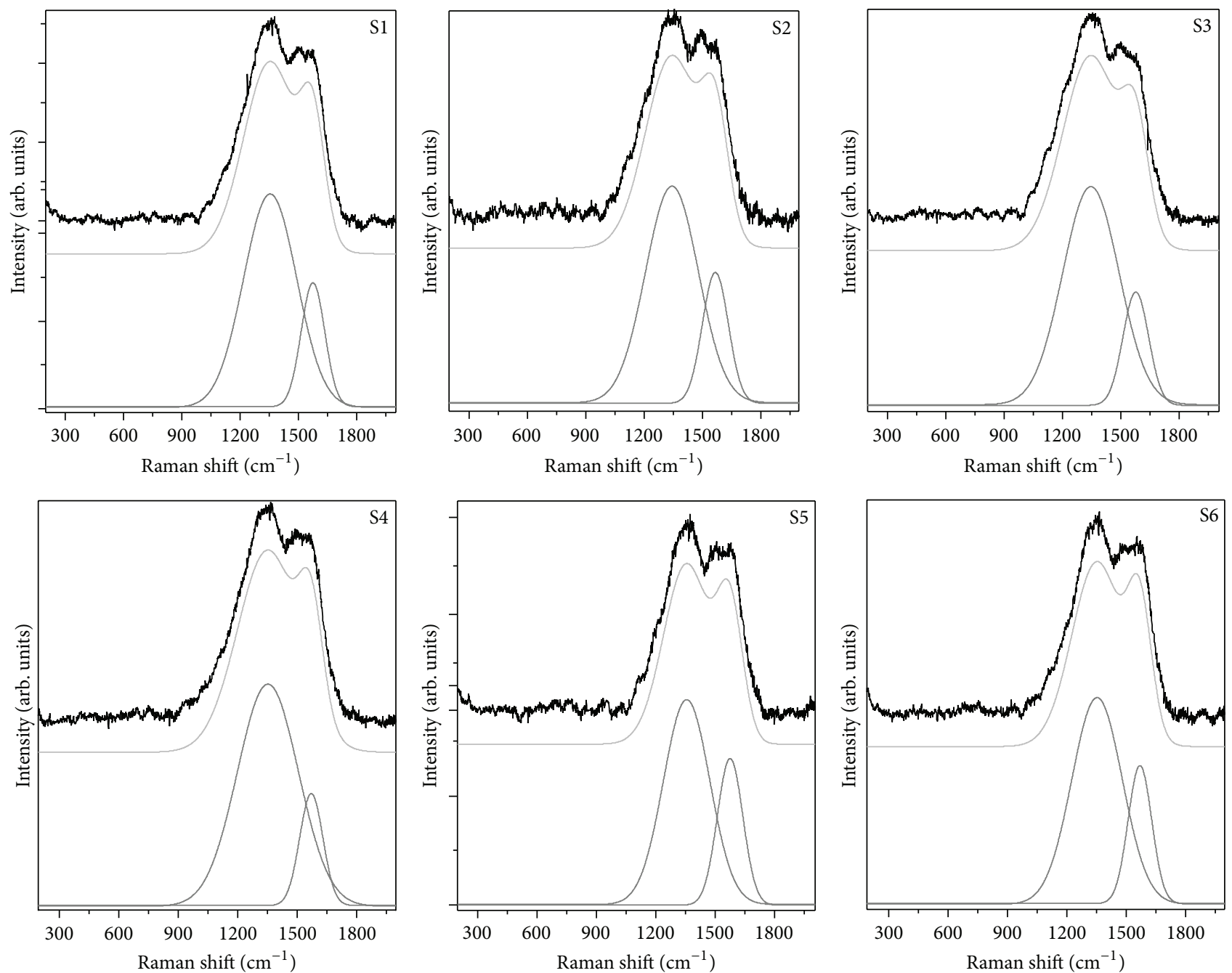

FIGURE 3: Raman spectra of the S1-S6 series of the $\alpha-\mathrm{CN}_{x}$ films deposited on glass as substrate and their corresponding fitted Lorentz functions.

opposite behavior, that is, ordering and increasing of the $\mathrm{sp}^{3}$ content $[10,14,17]$. For carbon materials with a highly disordered structure, where the atoms are not $100 \% \mathrm{sp}^{2}$ bonded, the Three-Stage Model (TSM) provides an alternative that allows correlating the position of the $G$ band and the values of $I_{D} / I_{G}$ to the $\mathrm{sp}^{2} / \mathrm{sp}^{3}$ bonding ratio [17]. Hence, from the data collected in Table 2, the present $\mathrm{CN}_{x}$ films can be classified into Stage 2, characterized by $\mathrm{sp}^{3}$ increasing from 0 to $20 \%$ and the transition from nanocrystalline materials up to highly disordered. As mentioned above, the position of the $G$ band is $1563 \pm 5 \mathrm{~cm}^{-1}$ yielding $\mathrm{sp}^{3}$ relative bonding content of $9 \pm 1 \%$, in agreement with the reported data obtained for sputtered samples.

From these observations we could suggest that these materials present a drastic change, at the nanometric scale, with the increase of the $\mathrm{C} / \mathrm{N}$ ratio, which is later on reflected in the gap values and the displacement of the $G$ band. In addition, the intensity and the full width at half maximum (FWHM) of the $D$ band can be related to the clustering and the disorder degree. In this sense, both follow the same behavior as the $G$ band.

On the other hand, it is well known that the in-plane crystalline size of the graphitic domains $\left(L_{a}\right)$ in graphitic clusters can be calculated by using the following relation: $L_{a}(\mathrm{~nm})=C^{\prime}\left(I_{D} / I_{G}\right)^{-1}$, where $C^{\prime}$ is the scaling coefficient derived by Tuinstra-Koenig (T-K) model [20]. This expression was developed for disordered graphite with $100 \% \mathrm{sp}^{2}$ bonded atoms and it is valid down to a critical cluster size of $2 \mathrm{~nm}$. In highly disordered carbon materials, the presence of defects and the possible decrease of $L_{a}$ below $2 \mathrm{~nm}$ point out a lower number of carbon hexagonal rings in the network. Consequently, the intensity of the $D$ mode and the ratio $I_{D} / I_{G}$ tend to decrease and the $\mathrm{T}-\mathrm{K}$ approximation is no longer valid. Hence, the model used to depict these transitions, developed by Ferrari-Robertson (F-R), can be expressed as follows: $L_{a}(\AA)=\left[\left(\left(I_{D} / I_{G}\right) / 0.0055\right)\right]^{1 / 2}[21]$. In this regime, the aromatic clusters become smaller and more disordered $[14,15]$. When the disorder increases, the $\mathrm{sp}^{2}$ phase changes 


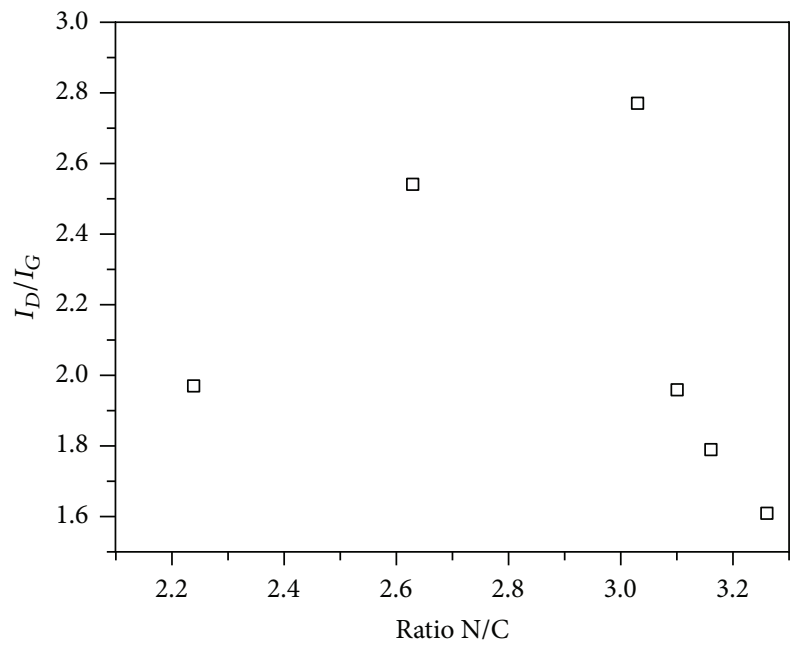

(a)

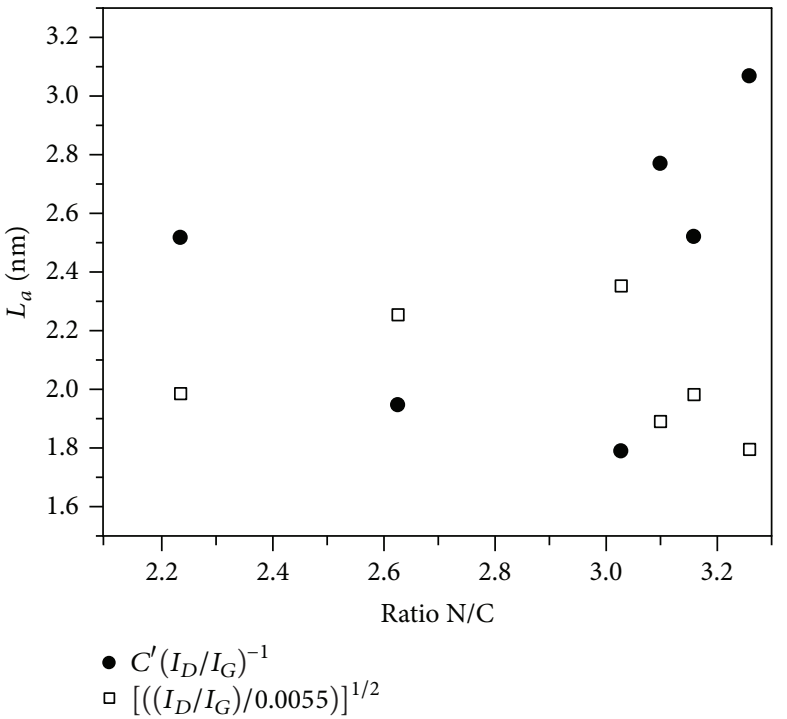

(b)

FIgure 4: Changes in $I_{D} / I_{G}$ versus the N/C ratio (a). Variation of $L_{a}$, obtained from the Tuinstra-Koenig and Ferrari-Robertson models versus the $\mathrm{N} / \mathrm{C}$ ratio.

from ring to chain structures, while at the final stage when $\mathrm{sp}^{3}$ bonds are introduced $\mathrm{sp}^{2}$ bonds become strongly localized [22].

Plotting of $I_{D} / I_{G}$ ratio and $L_{a}$ values, in relation to the N/C content, shows a nonusual behaviour that could be directly related to the $\mathrm{sp}^{2} / \mathrm{sp}^{3}$ bonding ratio. Figure 4(a) shows an increase in the $I_{D} / I_{G}$ ratio for the films with $\mathrm{N} / \mathrm{C}$ content below 3.03; later on, the ratio decreases with the increase in the $\mathrm{N} / \mathrm{C}$ ratio up to 3.26 . If the $I_{D} / I_{G}$ ratio decreases, because the introduction of nitrogen makes the $\mathrm{sp}^{2}$ clusters become larger, we could speculate that the films with low $I_{D} / I_{G}$ ratio (N/C content from 3.10 to 3.26 ) present this feature $[10,14]$.

Figure 4(b) represents the variation in $L_{a}$, obtained from the Tuinstra-Koenig and Ferrari-Robertson models, with respect to the $\mathrm{N} / \mathrm{C}$ content. Applying the T-K formula, $L_{a}$ values decrease from 2.59 to $1.79 \mathrm{~nm}$ as the N/C content increases from 2.24 to 3.03; however, at higher N/C concentrations, $L_{a}$ increases directly proportional to the N/C content. This situation indicates that the films with N/C content higher than 3.16 present a tendency toward ring-like structure rather than chain formation. On the other hand, $L_{a}$ values derived from the F-R equation increase from 1.98 to $2.35 \mathrm{~nm}$ as the N/C content increases from 2.24 to 3.03 ; later on, $L_{a}$ decreases inversely proportional to the N/C content. These variations indicate that the aromatic clusters become smaller and more disordered if $L_{a}$ is smaller than $2 \mathrm{~nm}$. As the disorder increases, the $\mathrm{sp}^{2}$ phase changes from ring to chain structures.

These analyses could provide a clear evidence about how the N/C content modifies the $\mathrm{sp}^{2} / \mathrm{sp}^{3}$ bonding ratio and the order/disorder degree in the films [13], as mentioned before. However, these present results do not present a good correlation. According to the shifting of the $G$ band and the results derived from the T-K model, films with $\mathrm{N} / \mathrm{C}$ ratio $\leq$ 3.03 present low $\mathrm{sp}^{3}$ contents and high disorder in bonding; while those films with $\mathrm{N} / \mathrm{C}$ ratio $\geq 3.16$ have high $\mathrm{sp}^{3}$ content and ring formation. In contrast, results obtained from the $I_{D} / I_{G}$ ratio and the F-R model follow the opposite trend. This indicates how the visible Raman spectra depend primarily on the ordering of $\mathrm{sp}^{2}$ sites and not on the fraction of $\mathrm{sp}^{2}$ sites, as has been discussed before.

Another important feature is the $G$ band dispersion $\left(G_{\text {disp }}\right)$ since allows observing the shift of this band and yields to estimate the density $(\rho)$ of the $\mathrm{CN}_{x}$ films. Thus, we can empirically define the $G$ band dispersion as follows [17]:

$$
G_{\text {disp }}\left(\mathrm{cm}^{-1}\right)=\frac{G_{\text {pos }}(244 \mathrm{~nm})-G_{\text {pos }}(633 \mathrm{~nm})}{(244-633) \mathrm{nm}}
$$

where $G_{\text {pos }}$ is the position of $G$ at the wavelength of 244 and $633 \mathrm{~nm}$. Results collected in Table 2 show a slight dispersion ranging from 0.21 to $0.24 \mathrm{~cm}^{-1}$. From here, the density of the $\mathrm{CN}_{x}$ films can be extracted by fitting the $G_{\text {pos }}$ values in a relationship proposed by $\mathrm{FR}$, where the $G_{\text {disp }}$ is plotted as a function of $\rho\left(\mathrm{cm}^{3} / \mathrm{g}\right)$, for different carbon nitride films deposited by cathodic arc and sputtering. Results collected in Table 2 show slight density variations ranging from 2.68 to $2.85 \mathrm{~g} / \mathrm{cm}^{3}$, presenting good agreement with experimental values reported recently [17].

It is well known that the synthesis methods have an important effect on the $\mathrm{sp}^{2} / \mathrm{sp}^{3}$ bonding ratio of the produced carbon nitride films $[11,13]$. In this sense, those obtained from sputtering techniques, such as the present ones, are mainly $\mathrm{sp}^{2}$ bonded, even when the nitrogen content in the samples is higher than $20 \%$. This situation is also reflected in the spectra of Figure 3, where the presence of the $D$ and $G$ bands is a 


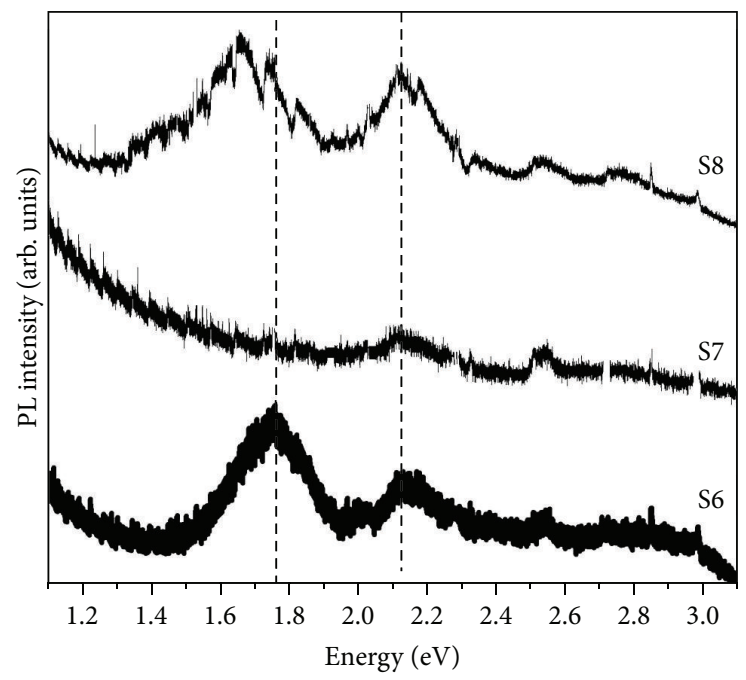

Figure 5: PL spectra of the S7 and S8 $\alpha-\mathrm{CN}_{x}$ films deposited on silicon and quartz as substrates, respectively. The included S6 spectrum is included as reference.

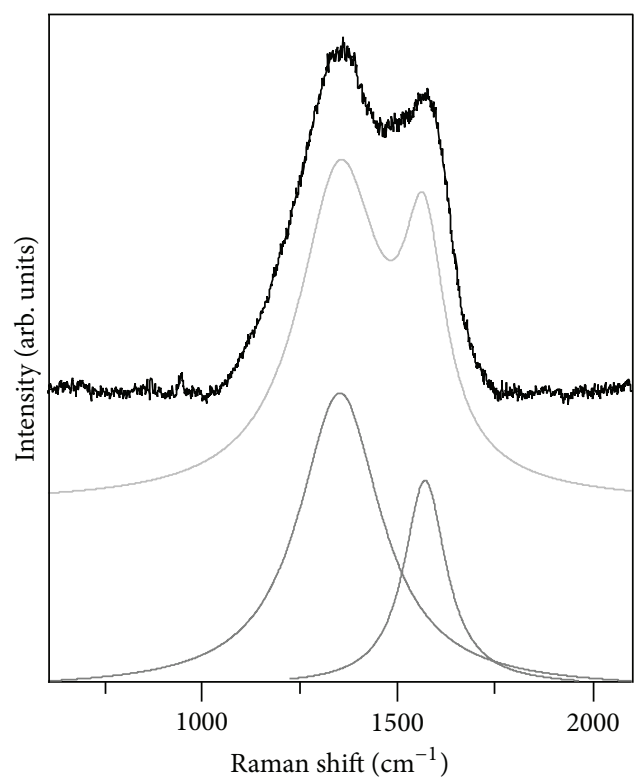

(a)

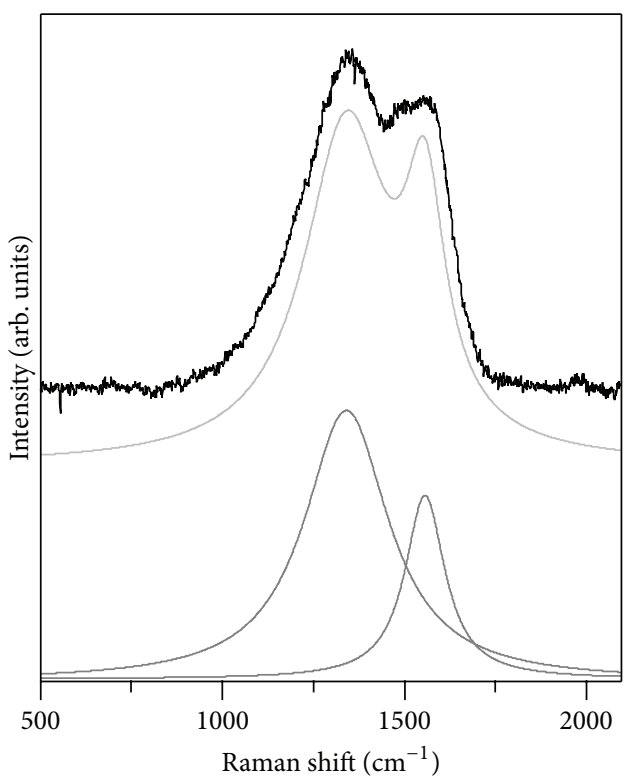

(b)

FIGURE 6: Raman spectra of the S7 (a) and S8 (b) $\alpha-\mathrm{CN}_{x}$ films deposited on silicon and quartz as substrates, respectively.

consequence of the $\mathrm{sp}^{2}$ sites which have $\approx 55$ times larger cross section than the $\mathrm{sp}^{3}$ sites [23].

\section{2. $\mathrm{CN}_{x}$ Films Deposited on Silicon and Quartz as Substrates.} PL spectroscopy studies of carbon nitride films with different substrates were made in order to detect the influence of the substrate on the optical properties of the samples. Figure 5 shows the PL spectra of $\mathrm{CN}_{x}$ films deposited (under similar conditions to S6) on silicon (S7) and quartz (S8) as substrates.

All spectra display the maximum located at $\approx 2.13 \pm$ $0.02 \mathrm{eV}$ associated with the $\mathrm{CN}_{x}$ film, providing evidence of good reproducibility of the deposition method. The PL of the sample on silicon as substrate does not have the peak at lower energy. On the other side, the sample deposited on quartz as substrate shows a peak associated with the PL of the quartz [24] at lower energy than the contribution made by the glass as substrate. These observations suggest that the PL contribution derived from the substrate must be taken into consideration carefully; even when the $\mathrm{CN}$ films have low nitrogen content, the signal associated with substrate could interfere with the PL analysis.

In the case of the Raman spectra, the S7 and S8 films follow the same behavior detected in the samples deposited on glass as substrate. In Figure 6, it is possible to observe that the $D$ band intensity and FWHM are bigger than the same features of the $G$ band, as was previously described for 
the series S1 to S6. These observations and the parameters collected in Table $2\left(L_{a}, G_{\text {disp }}\right.$, and $\left.\rho\right)$ suggest that the substrate does not modify the structure of the deposited film.

\section{Summary and Conclusions}

Amorphous carbon nitride films with high N/C ratio (ranging from 2.24 to 3.26 ) were successfully deposited on glass, silicon, and quartz as substrates by using the reactive sputtering method.

From the photoluminescence spectroscopy, we have identified two main contributions: a first signal associated with the $\mathrm{CN}_{x}$ film having a narrow peak located at $\approx 2.13 \pm$ $2 \mathrm{eV}$ emerging from the lon pair- $\pi^{*}$ state transitions and a second one coming from the substrates. In addition, results indicate an increase in the optical band gap from 2.11 to $2.15 \mathrm{eV}$ associated with the increase in the N/C ratio. From the Raman spectroscopy, we found that the features of the $D$ band (intensity and FWHM) are higher than those in the $G$ one, suggesting presence of clustering and high disorder degree. Variations on the $I_{D} / I_{G}$ ratio, between 1.51 and 2.58, were associated with the increase in the number and in the size of $\mathrm{sp}^{2}$ clusters; whereas the $I_{D} / I_{G}$ ratio was observed to decrease with the increase of the optical gap.

\section{Conflict of Interests}

The authors declare that there is no conflict of interests regarding the publication of this paper.

\section{Acknowledgments}

This work was supported by FOMIX-Veracruz under Projects 127966. Participation of Ayesha Margarita Courrech Arias (MICRONA) and Francisco Rodriguez Melgarejo (CINVESTAV-Querétaro) is acknowledged.

\section{References}

[1] G. Goglio, D. Foy, and G. Demazeau, "State of art and recent trends in bulk carbon nitrides synthesis," Materials Science and Engineering R: Reports, vol. 58, no. 7, pp. 195-227, 2008.

[2] X. Jiang, C. Zhuang, J. Zhao, and X. Jiang, "Structural and mechanical properties of low-density amorphous carbon nitrides by molecular dynamics simulations," Diamond and Related Materials, vol. 23, pp. 44-49, 2012.

[3] S. H. Mohamed, F. M. El-Hossary, G. A. Gamal, and M. M. Kahlid, "Optical properties of plasma deposited amorphous carbon nitride films on polymer substrates," Physica B: Condensed Matter, vol. 405, no. 1, pp. 254-257, 2010.

[4] M. Aono, T. Takeno, and T. Takagi, "Structural, electrical, and optical properties of amorphous carbon nitride films prepared using a hybrid deposition technique," Diamond and Related Materials, 2015.

[5] X.-H. Zheng, F.-E. Yang, L. Chen, Z.-L. Chen, R.-G. Song, and X.-H. Zhang, "Microstructure and mechanical properties of a$\mathrm{CN}_{x}$ films prepared by bias voltage assisted PLD with carbon nitride target," Surface and Coatings Technology, vol. 258, pp. 716-721, 2014.
[6] P. Wang, M. Hirose, Y. Suzuki, and K. Adachi, "Carbon tribo-layer for super-low friction of amorphous carbon nitride coatings in inert gas environments," Surface and Coatings Technology, vol. 221, pp. 163-172, 2013.

[7] J.-T. Zhang, C.-B. Cao, Q. Lv, C. Li, and H.-S. Zhu, "Optical and electrical properties of carbon nitride films deposited by cathode electrodeposition," Journal of Materials Science, vol. 38, no. 12, pp. 2559-2562, 2003.

[8] C. Y. Zang, X. P. Jia, H. A. Ma, S. S. Li, Y. Tian, and H. Y. Xiao, "Grow large high-quality diamonds with different seed surfaces," Chinese Physics Letters, vol. 23, no. 1, pp. 214-216, 2006

[9] M. F. Plass, C. Popov, B. Ivanov et al., "Correlation between photoluminescence, optical and structural properties of amorphous nitrogen-rich carbon nitride films," Applied Physics A, vol. 72, no. 1, pp. 21-27, 2001.

[10] H.-X. Han and B. J. Feldman, "Structural and optical properties of amorphous carbon nitride," Solid State Communications, vol. 65, no. 9, pp. 921-923, 1988.

[11] T. Katsuno, S. Nitta, H. Habuchi, T. Iwasaki, T. Itoh, and S. Nonomura, "Photoconductivity and photoluminescence of amorphous carbon nitride a- $\mathrm{CN}_{\mathrm{x}}$ films prepared by the layerby-layer method," MRS Proceedings, vol. 593, pp. 499-504, 2000.

[12] J. Wang, D. R. Miller, and E. G. Guillan, "Photoluminescent carbon nitride films grown by vapor transport of carbon nitride powders," Chemical Communications, no. 19, pp. 2258-2259, 2002.

[13] Y. Iwano, T. Kittaka, H. Tabuchi et al., "Study of amorphous carbon nitride films aiming at white light emitting devices," Japanese Journal of Applied Physics, vol. 47, no. 10, pp. 7842$7844,2008$.

[14] M. Fathallah, N. Alassimi, N. Alzayed, and R. Gharbi, "Nitrogen effects on optical and electrical properties of amorphous carbon," Materials Science Forum, vol. 636-637, pp. 423-429, 2010.

[15] N. Mutsukura, "Photoluminescence and infra-red absorption of annealed a-CN $\mathrm{CN}_{x}: \mathrm{H}$ films," Diamond and Related Materials, vol. 10, no. 3-7, pp. 1152-1155, 2001.

[16] S. E. Rodil, S. Muhl, S. Maca, and A. C. Ferrari, "Optical gap in carbon nitride films," Thin Solid Films, vol. 433, no. 1-2, pp. 119-125, 2003.

[17] A. C. Ferrari and J. Robertson, "Raman spectroscopy of amorphous, nanostructured, diamond-like carbon, and nanodiamond," Philosophical Transactions of the Royal Society of London A, vol. 362, no. 1824, pp. 2477-2512, 2004.

[18] A. C. Ferrari and J. Robertson, "Interpretation of Raman spectra of disordered and amorphous carbon," Physical Review B, vol. 61, no. 20, pp. 14095-14107, 2000.

[19] N. Larouche and B. L. Stansfield, "Classifying nanostructured carbons using graphitic indices derived from Raman spectra," Carbon, vol. 48, no. 3, pp. 620-629, 2010.

[20] R. J. Nemanich and S. A. Solin, "First- and second-order Raman scattering from finite-size crystals of graphite," Physical Review B, vol. 20, no. 2, pp. 392-401, 1979.

[21] F. Tuinstra and J. L. Koenig, "Raman spectrum of graphite," Journal of Chemical Physics, vol. 53, no. 3, pp. 1126-1130, 1970.

[22] A. C. Ferrari and J. Robertson, "Resonant Raman spectroscopy of disordered, amorphous, and diamondlike carbon," Physical Review B, vol. 64, no. 7, Article ID 75414, 2000. 
[23] W. Xu, T. Fujimoto, B. Li, and I. Kojima, "Characterization of the density, structure and chemical states of carbon nitride films," Applied Surface Science, vol. 175-176, pp. 456-461, 2001.

[24] B. G. Gorshkov, I. E. Gorbatov, Y. K. Danileiko, and A. V. Sidorin, "Luminescence, scattering, and absorption of light in quartz optical fibers and prospective use of these properties in distributed waveguide sensors," Soviet Journal of Quantum Electronics, vol. 20, no. 3, pp. 283-288, 1990. 

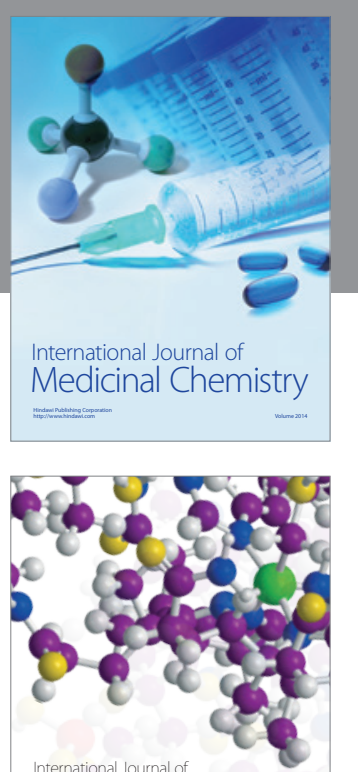

Carbohydrate Chemistry

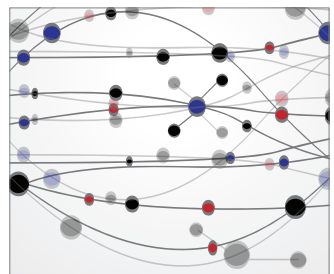

The Scientific World Journal
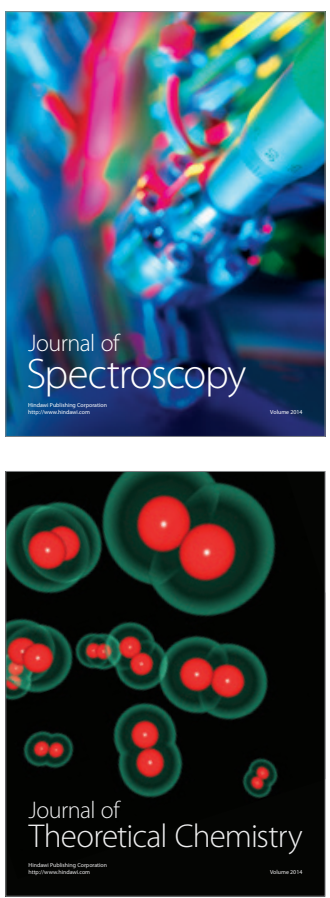
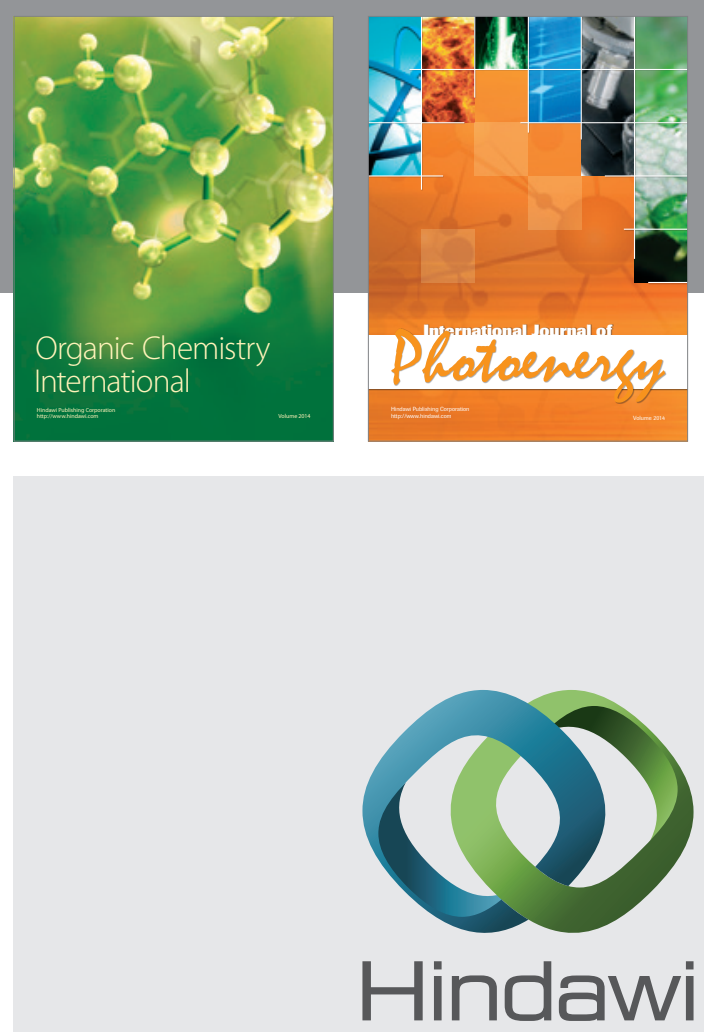

Submit your manuscripts at

http://www.hindawi.com

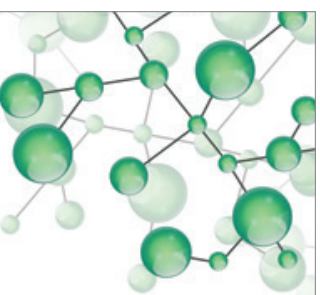

International Journal of

Inorganic Chemistry

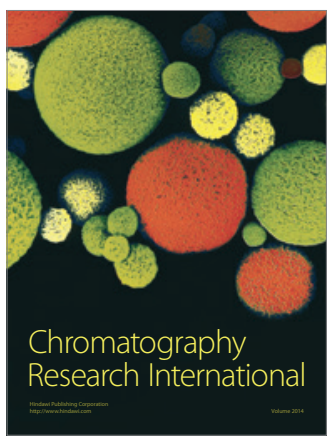

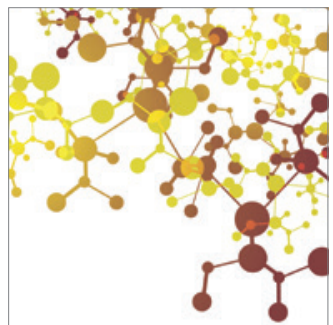

Applied Chemistry
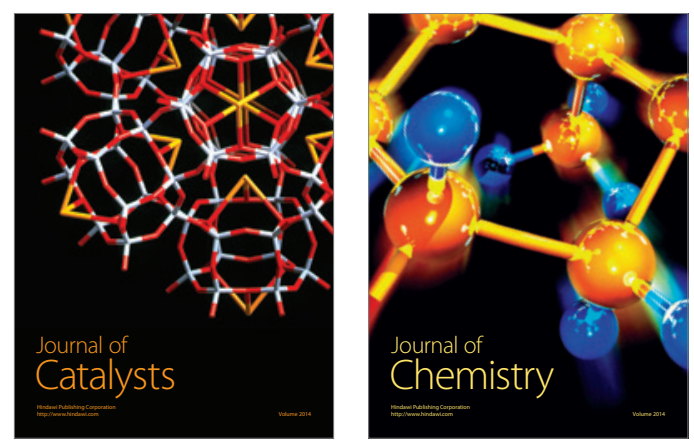
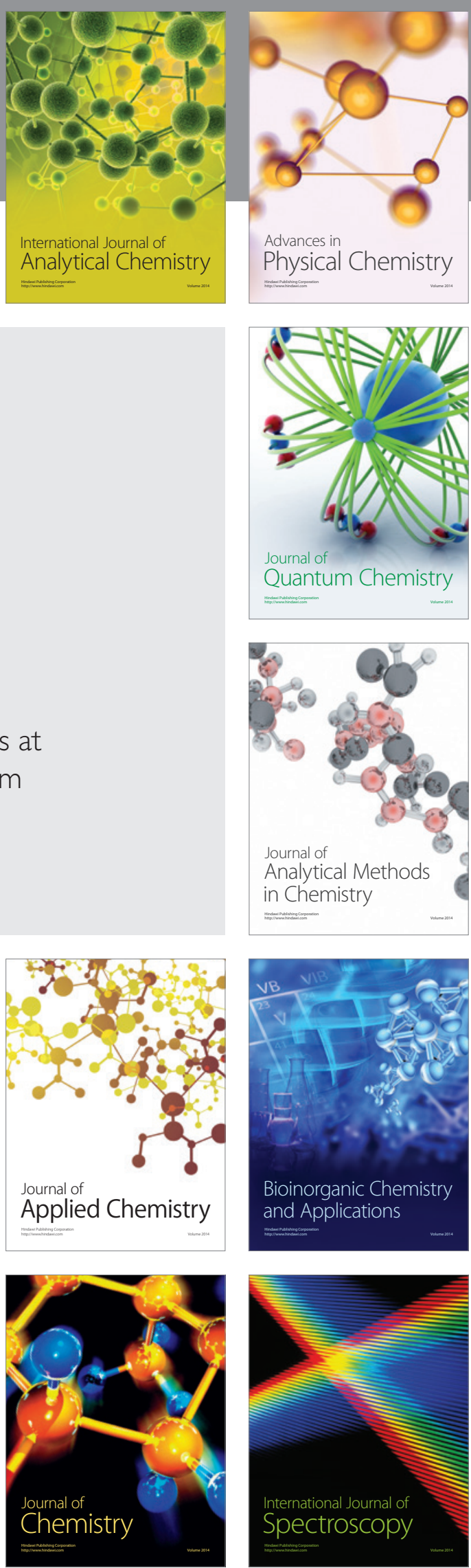